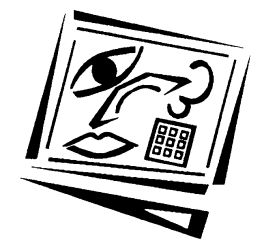

\title{
Impact of static graphics, animated graphics and mental imagery on a complex learning task
}

\author{
Feng-Qi Lai \\ Indiana State University \\ Timothy J. Newby \\ Purdue University
}

\begin{abstract}
The present study compared the impact of different categories of graphics used within a complex learning task. One hundred eighty five native English speaking undergraduates participated in a task that required learning 18 Chinese radicals and their English equivalent translations. A post-test only control group design compared performance differences following training between 5 groups of participants (control, concrete verbal imagery information, single static graphics, multiple gradient static graphics, and animated graphics) on both immediate and 4-week retention tests. Data analysis indicated all graphic groups significantly outperformed the control group immediately following training. A 4-week delayed test showed those originally receiving multiple gradient static graphics significantly outperformed all other groups except those receiving the animated graphics. Implications are discussed based on cognitive load and the cognitive theory of multimedia learning.
\end{abstract}

\section{Introduction}

For generations, graphics have been incorporated within educational materials to enhance learning (Macdonald-Ross, 1977; Rieber, 1994). As computer technology has advanced, the potential variety and overall quality of the graphics has increased. Such graphics now include pictures, cartoons, charts, maps, diagrams, outlines, videos, etc. Color, clarity, and animation are examples of enhanced features that are now readily used. Alesandrini (2002) explains that from an instructional viewpoint, graphics can facilitate learning: a) when used to represent actual people, places, or things; $b$ ) when the graphic helps to simplify difficult, complex, and/or abstract material (e.g., a company's organizational chart) ; or c) when used as an analogical bridge between familiar, already learned materials and unfamiliar, or to be learned materials (e.g., a graphic of a familiar truck to facilitate learning the functions of an unfamiliar red blood cell). Repeatedly, studies have shown that graphics can benefit comprehension, insight, and learning when properly selected and used within instructional materials (e.g., the review by Tversky, Morrison \& Betrancourt, 2002)

Mayer and his colleagues (e.g., Mayer, 2001; 2008, Mayer, Hegarty, Mayer \& Campbell, 2005; Mayer \& Moreno, 2002; 2003; Mayer \& Sims, 1994) have repeatedly examined the impact of graphics on learning as they developed their cognitive theory of multimedia learning. A key assumption within that theory is that as humans encounter new information, separate verbal and visual information processing systems are used. 
Derived from dual coding theory (Clark \& Paivio, 1991; Paivio, 1986), "The visual channel takes input initially from the eyes and ultimately produces pictorial representations; the verbal channel takes input initially from the ears and ultimately produces verbal representations" (Mayer \& Moreno, 2002, p. 110). Utilising both channels allows more information to be processed, as well as generating a greater number of potential integration links to information already within long term memory. In addition, if a memory trace in one channel is lost, it may still be available via the memory trace provided by the other channel (Kuo \& Hooper, 2004). Instructional graphics enable the visual channel within working memory to be utilised.

A second key assumption is based on cognitive load theory which focuses on the limited capacity of working memory (Paas, Renkl \& Sweller, 2003). Both verbal and visual information processing channels are severely limited and thus if too many words or too complex a picture are to be processed within their respective channels, overload can be created, "in which the learner's intended cognitive processing exceeds the learner's available cognitive capacity" (Mayer \& Moreno, 2003, p. 43). Understanding this assumption allows one to evaluate how an instructional message is designed, organised, and presented in order to reduce irrelevant and inefficient cognitive processing (Mayer, 2001). That is, the quality of the instructional graphic can impact upon how it is processed and what is gained from its use. The final assumption is based on a constructivist perspective of learning which promotes "the idea that meaningful learning occurs when learners actively select relevant information, organize it into coherent representations, and integrate it with other knowledge (Mayer, 1996; Mayer, 1999; Wittrock, 1989). In short, cognitive construction depends on the cognitive processing of the learner during learning" (Mayer \& Moreno, 2002, p. 111). This assumption indicates that instructional graphics will better enhance learning when they offer information and guidance to the learner for creating the needed structure (Mayer, 2001).

As identified by Tversky, et al., (2002) there are several key reasons why graphics can be utilised to enhance learning. First, they can make the learning more efficient. Pictures and other visuals help reduce the need for long textual descriptions. In such cases, a picture really can be "worth a thousand words." Thus the use of graphics may lead to more efficient processing of information by utilising the visual channel while reducing the information needed to be processed via the verbal channel. Second, well constructed graphics can organise complex materials so that key features are more readily ascertained and understood, as well as show spatial relations between important elements that otherwise may not be discovered by a learner. Based on Mayer's (2001, 2003) active processing assumption, well-designed graphics may provide the needed structure that allows learners to effectively select, organise, and integrate new information. Finally, by highlighting underlying structures, key processes, and relevance of the instruction, graphics can promote understanding, inference, potential discovery, and learner motivation. Moreover, cognitive load can be reduced as attention is directed to the significant elements and away from those items of less importance.

Based on these theoretical underpinnings, graphics can impact upon overall learning. Advances in computer technology capability have allowed for easier design, development, production, and presentation of graphics for instructional purposes. Not only has the number of graphics increased, but the overall quality and types of graphics have expanded. Increased availability has led to questions about what types 
of graphics are most advantageous for specific learning situations (Newby \& Lai, 2008). The question now becomes, when and what types of graphic should be used? To this end, the present study was designed to compare three categories of graphics, for example learner-produced, static (single and multiple), and animated/morphed, across a complex learning task, in order to measure their immediate and long term impact on learning.

The first category is based on mental imagery, where the learner is generally presented with a verbal cue and then mentally recalls the object and associates it with the new, to be learned information. For example, Kuo and Hooper (2004) found that when they gave their native English speaking, college age participants the task of associating unfamiliar Chinese characters with the appropriate English translations, learning increased when the participants were encouraged to create their own memory aids associating the characters to their meanings. For example, when presented with the character for winter, a vast majority of successful participants generated visual memory aids that included things such as "snow falling" or "footprints in the snow." These self-generated, meaningful mental images were used to facilitate the learning. Research investigating the use of mnemonics has suggested that when individuals are able to develop their own mental pictures/graphics, learning is enhanced (Bellezza, 1981).

A second category of graphics involves the presentation of a static graphic to the learner. In this case an actual picture, or chart, etc. is presented and key elements of the graphic can be highlighted. In order to show a process, an evolution, or a relationship, a series of gradient static graphics may also be incorporated. Such multiple static graphics allow the learner to see the key steps and then mentally complete what occurs between each of the individual static graphics in the series. Single static graphics and multiple static graphics have also been shown to be effective when used within instructional materials (Lewalter, 2003; Rieber, 1994; Tversky, et al., 2002).

With the advance of computer technology, a third category - animated graphics - is now readily available. This technology allows for graphics to now demonstrate the motion of a process (e.g., how blood flows through the chambers of the heart; how a toilet works) or even how through a morphing process a person, place, or thing can change over time. Lewalter (2003) noted the following about this type,

\footnotetext{
... animations seem to be superior for the visualization of spatial aspects and dynamic processes. ... As dynamic illustrations offer a complete model for generating a mental representation of motion, thereby reducing the level of abstraction of temporal ideas, they should support deeper understanding than static visuals do. When static visuals like pictures are used, learners are forced to infer this model on their own. One may, therefore, expect dynamic visuals to be more helpful in fostering the learning process if motion in three-dimensional space is a relevant aspect of the learning material" (p. 178)
}

Although in several comparison studies researchers have not found animated graphics to produce greater levels of learning and comprehension than static graphics (e.g., Kriz, 2002; Mayer, Hegarty, Mayer \& Campbell, 2005), a recent meta-analysis found that when animations contain certain levels of realism or are focused on proceduralmotor skills, they facilitate better learning outcomes than static graphics (Höffler \& Leutner, 2007). In a series of studies Ayres, Marcus, Chan and Qian (2009), as well as Wong et al., (2009) confirmed these findings. Tversky, et al. (2002) outlined the 
conditions under which animations should prove most beneficial. They explain that the benefits of animations "should be evident especially for continuous rather than discrete changes, in particular, for manner of change and for microsteps, the subtle and intricate timing relations among parts of a complex system" (p. 258). In addition, Wouters, Paas and van Merrienboer's (2008) review of cognitive load research identified specific design guidelines for the effective use of animated models.

The focus of the present study was to examine and compare each of these three categories of graphics across a single complex learning task for both immediate and longer retention time periods. To this end, the present study used Chinese radicals as the subject content, e.g.

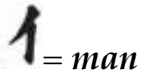

A great number of Chinese characters, e.g.,<smiles>[111InH]</smiles>

are composed of two elements: the radical (the pictorial component) and the sounding component. Radicals relate to the meaning of Chinese characters while the sounding components relate to character pronunciation (Shu, 1988). Participants were asked to study a number of unique radicals with their associated English translations. Subjects were then asked to recognise the radical when given the translation, recognise the translation when given the radical, or derive the correct translation when given a novel character that included a radical that had previously been studied.

For this task, graphics should play a key role. As explained by Kuo and Hooper (2004),

\begin{abstract}
Many of the earliest Chinese characters were pictographs... The ancient Chinese created written language by drawing pictures of objects according to their shape and form, rather than their sound. Pictographs referred to concrete objects, such as animals, plants, humans and their attributes, and phenomena in nature. Over time, many contemporary characters emerged from extant pictographs. New characters were formed by combining two or more symbols to represent more complex or abstract concepts (p. 24).
\end{abstract}

Although these radicals were based on graphical figures that at one time were closely associated with their current meaning; they have evolved and now are quite abstract with little, if any, apparent concrete association between current radicals and their present meanings. Through the use of graphics this evolutionary process can be depicted; moreover, viewing the evolution from the concrete picture to the more abstract version of today may help learners to more readily associate current radicals with their associated meanings. This task allowed for the following key research questions to be investigated: a) is there a difference in the immediate recall performance based on the type of instructional graphics used within the training materials?; b) did the overall effectiveness of the instructional graphics interventions change after a subsequent retention period?; and c) when an evolutionary process is critical to the learning, is optimal learning (both immediate and longer term) achieved by having all steps presented and completed by the instructional material (i.e., demonstrated via animation/morphing) or by showing the evolutionary process as discrete static steps? 


\section{Method and materials}

\section{Design and participants}

A post-test only control group design was used that involved five randomly assigned groups. One hundred eighty-five university undergraduate students who were native speakers of English participated in this study. They were enrolled in an educational psychology class at a large Midwestern university in the United States. These participants were chosen because they did not have prior knowledge of Chinese radicals, and they predicted their future careers would not be related to the Chinese language. Subjects volunteered for this study to meet a course requirement for participation in research and the study was conducted outside of the regular class meetings. A pilot study was undertaken in order to substantiate the design of the instructional materials. The 10 subjects of the pilot study had attributes similar to the subjects of the main experiment.

\section{Instructional treatments}

One group, the control, received no graphic aids or concrete verbal information that was assumed to help form mental imagery. The other four groups received different respective treatments. The five groups consisted of the following:

1. No cue group (NC, control group; $\mathrm{N}=38$ ),

2. Cue for mental imagery group (CMI, concrete verbal information; $N=37$ ),

2. Single static graphic group (SSG; $N=36$ ),

4. Gradient static graphic group (GSG; $=37)$, and

5. Animated graphic group $(\mathrm{AG} ; \mathrm{N}=37)$

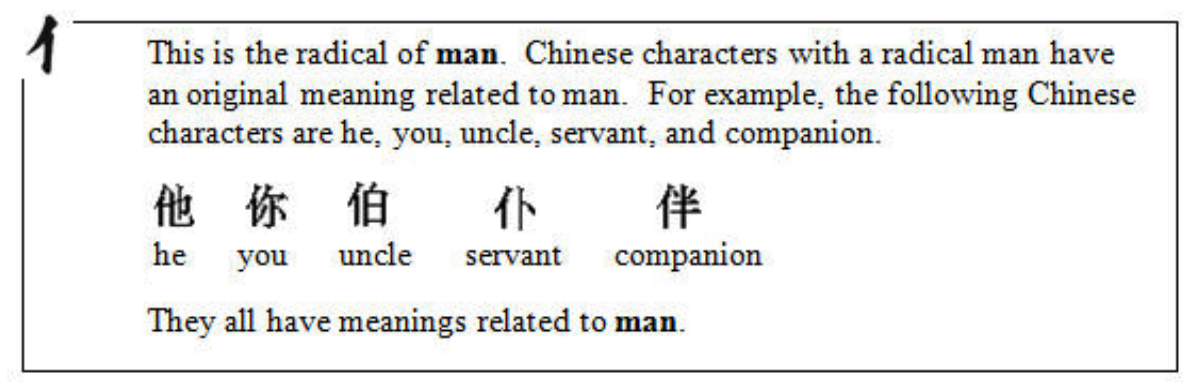

Figure 1: Example instructional materials used with the control group (NC)

For the CMI group, concrete verbal information (e.g., "This radical evolves from a picture of man") was added to the instructional materials (see Figure 2). For the SSG group, in addition to verbal information, a single static picture (see Figure 3) relating to the verbal information was also included.

The GSG and the AG groups had the same written instructions as the SSG group. However, these groups also received a prompt that required participants to click on the radical. For the GSG group, the click produced a series of four static pictures that appeared one by one vertically arranged on the left side of the screen. The four static pictures stayed on the screen depicting the evolution of the radical (see Figure 4; for an example of these instructional materials view http:/ / sapphire.indstate.edu/ flai/radi lesson/ radilesson.htm). 


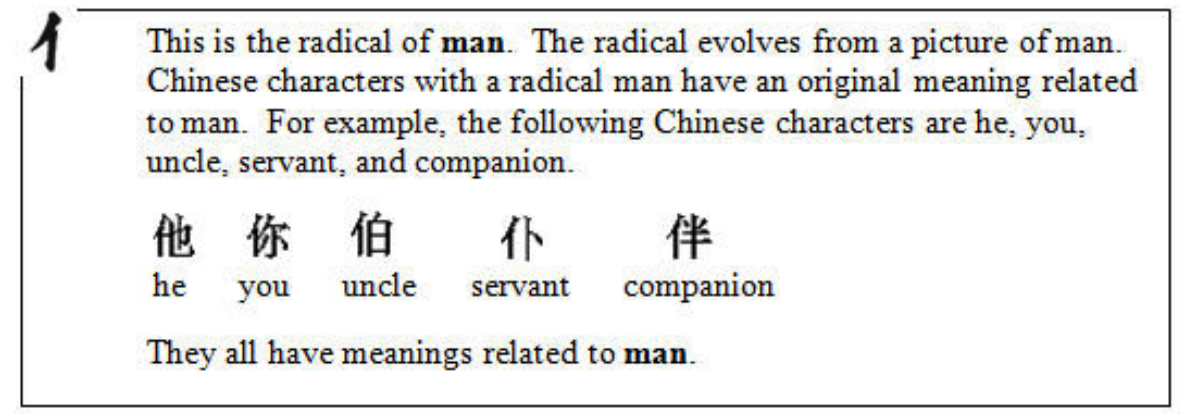

Figure 2: Example instructional materials used with the verbal information group (CMI)

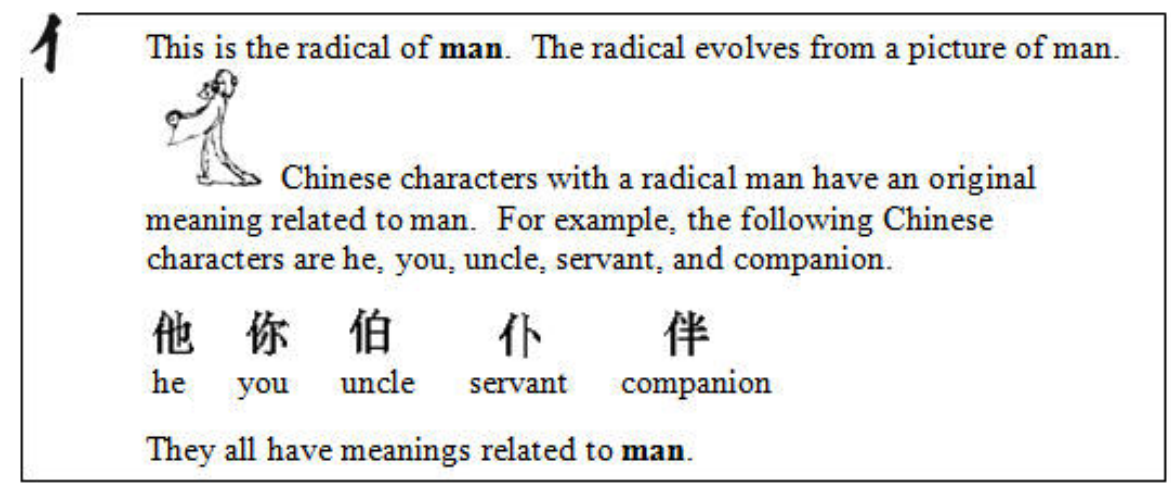

Figure 3: Example instructional materials used with the single static graphic group (SSG)

For the AG group, when the learners clicked on the radical, the same series of pictures were used; however, in this case the four pictures were faded in and out successively, one on top of the other to generate a morphing effect. This animation illustrated the evolution of the radical. As the morphing was completed, a second prompt allowed the participants in this group to click on the radical whereupon the first picture that represented the real object (e.g., "man") appeared and the radical moved up the screen until it was superimposed over that picture. Through this animation, participants were able to visualise how well the radical matched the graphic of the real object.

\section{Dependent variable: Post-tests}

The dependent variable was the learners' achievement on the content-related immediate and delayed post-tests. The two post-tests were identical except for the order of the items. The post-tests consisted of a recognition and recall test composed of three parts with a total of 36 multiple-choice questions, scoring one point for each correct answer. The questions (nine in part 1, nine in part 2, and eighteen in part 3) were designed to test declarative knowledge in different ways. For example, in the first part of the test, the participants were given an English word (e.g., "eye") and required to recognise the corresponding Chinese radical. Items in part 2 were used in a reverse manner to test learners' knowledge. The subjects were presented with a Chinese 
radical and were required to recognise and select its English translation. Items in part 3 required the transfer of the knowledge learned. Subjects were first given an English word and then required to judge, by the character's radical, which of four alternative Chinese characters had the meaning corresponding to the given English word. The Chinese characters selected had not been taught in the lesson, but they all contained radicals that had been taught. The internal reliability of the test was determined using Cronbach's alpha. The results were 0.87 for the immediate post-test $(n=185)$ and 0.85 for the delayed post-test $(n=174)$. These indicate the test was reliable with good internal consistency (George \& Mallery, 2003).

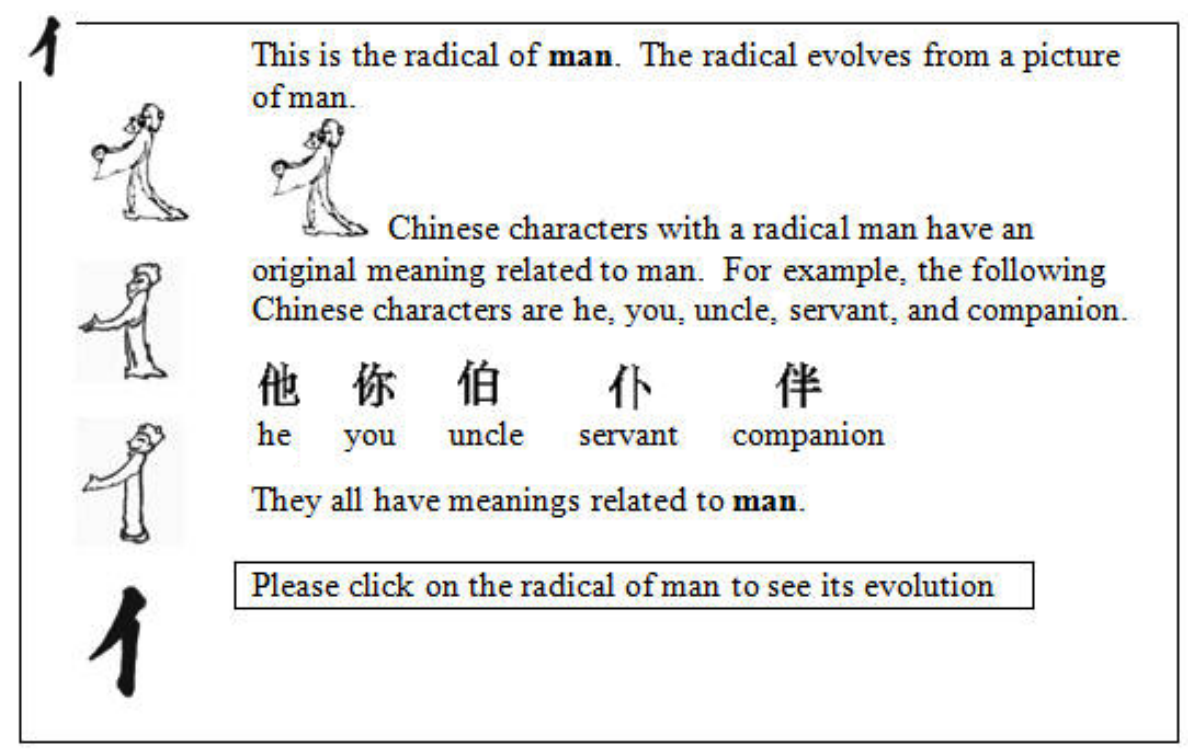

Figure 4: Example instructional materials used with the multiple/gradient static graphic group (GSG) and also adapted and used with the animation graphic group (AG)

\section{Instructional materials and computer software}

The instruction used during the study was designed using Adobe Authorware. All five versions were composed of three main sections: (a) the instructional materials for 18 different Chinese radicals, (b) the content-related post-test (three test sections), and (c) the delayed content-related post-test (three test sections). Test data including the subjects' performance, and demographic information were all recorded by the computer to an outside file. On average, approximately 20 to 30 minutes were spent completing all sections of the materials. For the delayed post-test, when the subject logged in, only the content-related post-test part (three test sections) was implemented.

\section{Implementation procedures}

Two weeks prior to the onset of the full study, the participants signed an informed consent form and took a prior knowledge test that was designed for screening out those who had knowledge of the Chinese language. The subjects also scheduled the date and time for 1) the Chinese radical lesson followed by the immediate post-test; 
and 2) the content-related delayed post-test. The delayed post-test was scheduled exactly four weeks after the scheduled Chinese radical lesson. For their participation, participants were first contacted and screened during the initial week of the fall semester. The initial training and post-test took place during the third week of September and the final delayed post-test occurred four weeks later during the third week of October of that same semester.

\section{Results}

One-way analysis of variance (ANOVA) was used to determine whether there were significant differences among the mean scores of the different groups. A preliminary analysis of quantitative data was conducted to examine the aptness of the model for the data collected. The results of the preliminary analysis indicated that the one-way analysis of variance was appropriate for the analysis of the test achievements.

\section{Immediate post-test}

According to the one-way analysis of variance, there was a significant difference among groups for the immediate post-test at an alpha of $.05: F(4,180)=5.08, \mathrm{p}=.001$, and effect size $=.59$. The results of the follow-up Tukey HSD comparison indicated that the four experimental groups all significantly outperformed the control group $(\mathrm{NC})$ in the immediate post-test (i.e., NC vs. CMI: $\mathrm{p}<.05$, effect size $=.56$, NC vs. SSG: $\mathrm{p}<.05$, effect size $=.50, \mathrm{NC}$ vs. GSG: $\mathrm{p}<.001$, effect size $=.74$, and NC vs. AG: $\mathrm{p}<.05$, effect size $=.56$ ); however, no significant differences were noted when comparing performances across the four experimental groups (i.e., CMI, SSG, GSG, AG). Table 1 highlights the mean and standard deviation of the scores achieved on the immediate post-test, and Figure 5 visually compares group mean scores.

Table 1: Mean scores and standard deviation for the immediate and delayed post-tests

\begin{tabular}{|l|c|c|c|c|c|c|c|}
\hline \multirow{2}{*}{ Group } & \multicolumn{3}{|c|}{ Immediate post-test } & \multicolumn{3}{c|}{ Delayed post-test } & Between test \\
\cline { 2 - 9 } & $\mathrm{N}$ & Mean & Std dev. & $\mathrm{N}$ & Mean & Std dev. & differences \\
\hline NC (No cue, control) & 38 & 22.6 & 7.89 & 36 & 15.11 & 6.63 & 7.49 \\
\hline CMI (Cue for mental imagery, group 2) & 37 & 27.10 & 6.81 & 32 & 19.78 & 6.53 & 7.32 \\
\hline SSG (Single static graphic, group 3) & 36 & 26.63 & 4.44 & 35 & 17.97 & 5.88 & 8.66 \\
\hline GSG (Gradient static graphic, group 4) & 37 & 28.54 & 4.62 & 37 & 24.00 & 6.39 & 4.54 \\
\hline AG (Animated graphic, group 5) & 37 & 27.1 & 5.93 & 34 & 21.56 & 5.61 & 5.54 \\
\hline
\end{tabular}

\section{Delayed post-test}

Exactly four weeks following the administration of the immediate post-test, a delayed post-test was administered to the participants of each of the groups. Table 1 and Figure 5 also show and depict the respective mean scores for this test. A second one-way analysis of variance was completed to measure the difference in group performances following the four week retention period. An overall significant difference was noted between the groups at an alpha of $.05(F(4,169)=10.73, \mathrm{p}<.001$, and effect size $=.87)$. In this case, the Tukey HSD comparison indicated significant performance differences between the control group and most of the experimental groups (i.e., NC vs. CMI: $\mathrm{p}<.05$, effect size $=.70, \mathrm{NC}$ vs. GSG: $\mathrm{p}<.001$, effect size $=1.34$, and NC vs. AG: $\mathrm{p}<.001$, effect size $=.97$ ), as well as between several of the experimental groups (i.e., GSG vs. CMI: $\mathrm{p}<.05$, effect size $=.65$, and GSG vs. SSG: $\mathrm{p}=.001$, effect size $=.94$ ). 


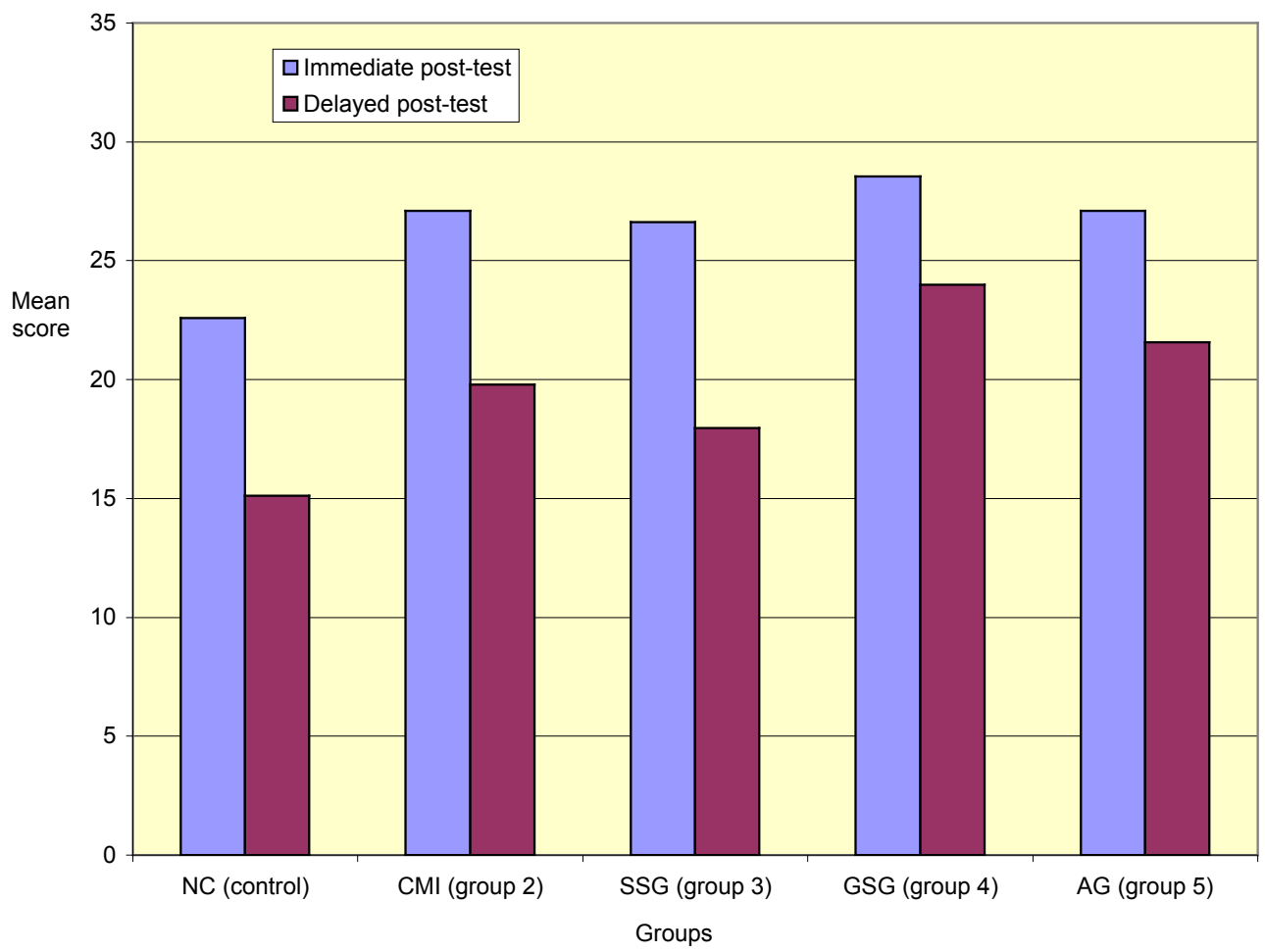

Figure 5: Mean scores of the five groups for the immediate and delayed post-tests

\section{Between test differences}

A final comparison was completed between the groups' performance differences between the two tests. As expected (see the final column in Table 1), all groups performed better immediately following exposure to the instructional materials than after a four week delayed time period. As also shown in Figure 5, the gradient static group (GSG) had the smallest amount of difference between the immediate and delayed post-test scores; whereas, the single static group (SSG) recorded the greatest amount of difference between the two tests.

\section{Discussion}

From these results several interesting points can be concluded. First, this was a difficult, highly interfering, paired associate learning task in which participants were initially asked to identify paired Chinese radicals and their associated English translation. In addition, they were required to transfer this learning in order to decipher novel, complex Chinese characters and identify which character contained the related radical when presented with its English translation. The difficulty of the task increased as a total of 18 pairs of radicals and their English translations were sequentially presented. Each pair was reviewed only as it was introduced, with no review or practice allowed after the initial presentation. 
Second, following the training, results from the immediate post-test showed that all treatments involving graphics and graphical imagery - cue for mental imagery (CMI), single static graphic (SSG), gradient static graphic (GSG), and animated graphic (AG) had significantly higher performance levels than those individuals who did not have the written cues within their materials (no cue (NC) - control). For the immediate recall test, simple verbal prompts (e.g., "this radical evolves from a picture of a man") facilitated recall. Each of the 18 concepts was concrete and tangible (e.g., knife, tree, mountain, man, horse) and thus relatively easy for individuals within the CMI (verbal imagery) to generate personally relevant mental images that could be associated with the given radical and the concept's English translation.

Research on the use of self-generated mental images in similar paired associate learning situations has been successful (e.g., Kuo \& Hooper, 2004). Explanations include the benefits of increased amounts of cognitive processing required to recall and associate the stored image, as well as the personal familiarity with the recalled image. Previous research with mental imagery indicates that concrete/tangible concepts are more readily created and associated by learners than those that are more abstract (Paivio, 1971). It would be interesting to see if these participants would have performed as well if some or all of the concepts were more abstract in nature, thus requiring additional cognitive processing. To a point, increased levels of cognitive processing facilitates learning; however, if the demands on cognitive load become too great, results may begin to indicate a lessening of the positive impact for self-generated visuals.

In addition to those using self-generated graphics, it was shown that presenting individuals with single, gradient, or animated graphics also significantly improved immediate post-test performances. According to the multimedia principle (Clark \& Mayer, 2007, p. 68) "people learn more deeply from words and graphics than from words alone." In one way, graphics used in addition to text require greater levels of active processing, as learners must interpret the graphic and determine how it is associated, organised, and/or related to the textual material. Greater processing brings about higher levels of learning, subsequently, those participants presented with both graphics and text should have completed more processing, resulting in greater levels of learning compared to those that processed the text only.

In addition, based on the cognitive theory of multimedia learning (Mayer, 2005), working memory within the human information processing system consists of both the auditory/verbal as well as the visual/pictorial channels for processing information. Within each of the channels only a limited amount of processing can occur at any one time. While the NC had all information provided through a single sensory channel, those participants within the SSG, GSG and the AG groups had the to be learned information presented through both verbal and visual channels. Working memory is severely limited in both quantity and duration; however, it appears that processing novel information through two channels may reduce overall cognitive load and thus facilitate learning (Sweller, 2005).

A third interesting point from this study focuses on the four-week delayed post-test results and how that helps to identify the longer term impact of the various types of graphics used in this study. Not surprisingly, without opportunities to repeat the training or to complete practice or review sessions between the initial training and the four-week delayed post-test, scores for all groups decreased. It is interesting however, 
to review the degree of score decline and note the differences across the various types of graphics. As illustrated in Figure 5, the long term effectiveness of the different types of graphics began to be revealed. Those groups receiving the gradient static graphics (GSG), for example, scored the highest on both tests and performed significantly higher on the delayed post-test than the control (NC), the verbal imagery (CMI), and the single static graphic (SSG) groups. A possible explanation may focus on the degree of active processing required by the various types of graphics. For example, those individuals within the SSG group had a single picture to process and organise with the text materials and then integrate with related prior knowledge in long term memory.

Although this single graphic allowed for increased performance on the immediate post-test, it appears to have waned in its effectiveness after the 4-week delay. After that delay, there was no performance difference between those who received the single static graphic and those in the control group. From another perspective, however, those within the gradient static group (GSG) not only had several additional graphics, but also needed to mentally animate the pictures in order for the evolution to be completed; thus requiring more mental processing and perhaps greater subsequent retention. In addition, when integrating this new set of graphics within GSG members' long term memories, the added graphics provided a greater number of recall cues that could have enhanced recall. Although following a 4-week delay some decline in performance was noticed, it was less of a decline than demonstrated by any of the other groups.

Another interesting aspect of this study is to examine the overall impact of the animated/morphing (AG) group. For both tests, these participants performed significantly higher than the control group, but not significantly different from any of the other graphic treatment groups. Overall, the decline in scores between the immediate and the delayed post-tests (Figure 5) was more than the gradient static group (GSG) but not as much as reported by all other groups. That is, animated presentations of the graphics, even without repeated practice and rehearsal, appeared to facilitate initial learning of the radical-English translation pairs. Moreover, a large portion of what was learned was retained over the delayed time period.

Although animation has been shown to pique the attention of learners, frequently it has been shown to not be as effective as a presentation of a series of static graphics (Tversky, et al., 2002). This may be attributed to the required cognitive processing imposed by the animation. In the present study, the animation showed the evolution of the Chinese radical from the initial concrete graphic to its present day form. Participants needed only to passively watch the animation to see the occurrence of the evolution. Those within the gradient static graphic group, however, had to participate more actively and mentally create the evolution from one graphic to the next. In addition, in order to grasp the evolution and the association between the English translation and the target radical, individuals in the animated group viewed the animation and then cognitively held the full animation within memory in order to make the appropriate paired association. Although subjects appeared to be able to complete this specific task to a great degree, such animations are so transitory, but yet still carry similar levels of detail as the gradient static graphics, that their demand on cognitive load is increased (Clark \& Mayer, 2007). In such a case, it would be predicted that those within the gradient static graphics group would have less demanding levels of cognitive load as they were to view each static graphic independently and did not have to hold all graphics in memory at the same time. 


\section{Conclusions}

The first research question for this study focused on the immediate recall performance, given the different forms of graphics within the instructional materials. Participants in each of the graphic interventions showed significantly greater levels of performance than those individuals who did not receive some form of graphical intervention. As predicted by the multimedia principle, those receiving text and graphics consistently outperformed those who received textual materials only. In this case, however, even a textual cue to mentally imagine a self-generated related graphic appeared to improve immediate post-test performance.

Investigating the second and third research questions began to reveal differences in the various types of graphics used in the training. Participants receiving a set of gradient static graphics reported higher scores for both immediate and delayed post-tests when compared with participants from other groups. In future studies it would be interesting to examine the impact of various amounts of rehearsal and/or practice on performance levels, given the various forms of training. Those in this study received only a very restricted amount of association between the pairs of items, and further investigations are needed to examine whether the different graphic interventions can be maintained over delayed time periods, through various forms of rehearsal and / or practice. It is also important to note that the difference between those receiving the gradient static graphics and those receiving the animation was not statistically significant. The only difference between these groups was how the identical sets of graphics were delivered to the participants and the degree of mental processing required because of that delivery. Questions focused on altering the speed of the animation delivery and the overall time between training and testing could produce increased levels of differences between these groups as well as subsequent recommendations on when and why the different types of graphics should be incorporated.

Increased levels of technology capabilities have opened the possibility for greater use of graphics within instructional materials. Their use can prove beneficial to learning. With various types of graphics readily available, making an appropriate selection decision should be based on sound principles and research.

\section{References}

Alesandrini, K. (2002). Visual constructivism in distance learning. USDLA Journal, 16(1). http: / / www.usdla.org/html/journal/JAN02_Issue/article03.html

Ayres, P., Marcus, N., Chan, C. \& Qian, N. (2009). Learning hand manipulative tasks: When instructional animations are superior to equivalent static representations. Computers and Human Behavior, 25(2), 348-353. http:/ / dx.doi.org/10.1016/j.chb.2008.12.013

Bellezza, F. S. (1981). Mnemonic devices: classification, characteristics, and criteria. Review of Educational Research, 51(2), 247-275. http:/ / dx.doi.org/10.2307/1170198

Clark, R. C. \& Mayer, R. E. (2007). E-learning and the science of instruction. San Francisco: Pfeiffer.

Clark, J. M. \& Paivio, A. (1991). Dual coding theory and education. Educational Psychology Review, 3(3), 149-210. http: / / dx.doi.org/10.1007/BF01320076

George, D. \& Mallery, P. (2003). SPSS for Windows step by step: A simple guide and reference. 11.0 update, 4th ed. Boston: Allyn \& Bacon. 
Höffler, T. N. \& Leutner, D. (2007). Instructional animation versus static pictures: A metaanalysis. Learning and Instruction, 17(6), 722-738.

http:/ / dx.doi.org/10.1016/j.learninstruc.2007.09.013

Kriz, S. (2002). Understanding simultaneity and causality in static diagrams versus animation. In M. Hegarty, B. Meyer \& N. Hari Narayanan (Eds.), Lecture Notes in Computer Science, 2002, Volume 2317/2002, 327-335. Berlin: Springer-Verlag. http:/ / dx.doi.org/10.1007/3-54046037-3_32

Kuo, M. A. \& Hooper, S. (2004). The effects of visual and verbal coding mnemonics on learning Chinese characters in computer-based instruction. Educational Technology Research and Development, 52(3), 23-38. http:/ / dx.doi.org/10.1007/BF02504673

Lewalter, D. (2003). Cognitive strategies for learning from static and dynamic visuals. Learning and Instruction, 13, 177-189. http:/ / dx.doi.org/10.1016/S0959-4752(02)00019-1

Macdonald-Ross, M. (1977). Graphics in text. Review of Research in Education, 5, 49-85. http:/ / dx.doi.org/10.2307/1167172

Mayer, R. E. (1996). Learning strategies for making sense out of expository text: The SOI model for guiding three cognitive processes in knowledge construction. Educational Psychology Review, 8, 357-371. http: / / dx.doi.org/10.1007/BF01463939

Mayer, R. E. (1999). Research-based principles for the design of instructional messages: The case of multimedia explanations. Document Design, 1(1), 7-20. http: / / dx.doi.org/10.1075/dd.1.1.02may

Mayer, R. E. (2001). Multimedia learning. New York: Cambridge University Press.

Mayer, R. E. (2008). Learning and instruction, 2nd ed. Upper Saddle River, NJ: Merrill Prentice Hall.

Mayer, R. E. (2005). Cognitive theory of multimedia learning. In R. E. Mayer (Ed.), The Cambridge handbook of multimedia learning. New York: Cambridge University Press.

Mayer, R. E., Hegarty, M., Mayer, S. \& Campbell, J. (2005). When static media promote active learning: Annotated illustrations versus narrated animations in multimedia instruction. Journal of Experimental Psychology: Applied, 11(4), 256-265. http:/ / dx.doi.org/10.1037/1076898X.11.4.256

Mayer, R. E. \& Moreno, R. (2002). Aids to computer-based multimedia learning. Learning and Instruction, 12(1), 107-119. http: / / dx.doi.org/10.1016/S0959-4752(01)00018-4

Mayer, R. E. \& Moreno, R. (2003). Nine ways to reduce cognitive load in multimedia learning. Educational Psychologist, 38(1), 43-52. http:/ / dx.doi.org/10.1207/S15326985EP3801_6

Mayer, R. E. \& Sims, V. K. (1994). For whom is a picture worth a thousand words? Extensions of a dual-coding theory of multimedia learning. Journal of Educational Psychology, 86(3), 389-401. http: / / dx.doi.org/10.1037/0022-0663.86.3.389

Newby, T. \& Lai, F.Q. (2008). Instructional graphics: Effectiveness of single versus gradient static graphics. In J. Luca \& E. Weippl (Eds.), Proceedings of World Conference on Educational Multimedia, Hypermedia and Telecommunications 2008 (pp. 4321-4325). Chesapeake, VA: AACE. http: / / editlib.org/p/ 28984

Paivio, A. (1971). Imagery and verbal processes. New York: Holt, Rinehart and Winston. 
Paivio, A. (1986). Mental representations: A dual coding approach. Oxford, UK: Oxford University Press.

Paas, F., Renkl, A. \& Sweller, J. (2003). Cognitive load theory and instructional design: Recent developments. Educational Psychologist, 38(1), 1-4. http: / / dx.doi.org/10.1207/S15326985EP3801_1

Rieber, L. P. (1994). Computer graphics and learning. Dubuque, IA: Brown \& Benchmark.

Shu, N. C. (1988). Visual programming. New York: Van Nostrand Reinhold Company, Inc.

Sweller, J. (2005. Implications of cognitive load theory of multimedia learning. In R. E. Mayer (Ed.), The Cambridge handbook of multimedia learning. New York: Cambridge University Press, 19-30.

Tversky, B., Morrison, J. B. \& Betrancourt, M. (2002). Animation: Can it facilitate? International Journal of Human-Computer Studies, 57, 247-262. http: / / dx.doi.org/ 10.1006/ijhc.2002.1017

Wittrock, M. C. (1989). Generative processes of comprehension. Educational Psychologist, 24(4), 345-376. http: / / dx.doi.org/10.1207/s15326985ep2404_2

Wong, A., Marcus, N., Ayres, P., Smith, L., Cooper, G. A., Paas, F. \& Sweller, J. (2009). Instructional animations can be superior to statics when learning human motor skills. Computers in Human Behavior, 25(2), 339-347. http: / / dx.doi.org/10.1016/j.chb.2008.12.012

Wouters, P., Paas, F. \& van Merrienboer, J. G. (2008). How to optimize learning from animated models: A review of guidelines based on cognitive load. Review of Educational Research, 78(3), 645-675. http: / / dx.doi.org/10.3102/0034654308320320

\author{
Authors: Dr Feng-Qi Lai \\ Associate Professor and Program Coordinator, Educational Technology \\ Department of Curriculum, Instruction, and Media Technology \\ College of Education, COE 323C, Indiana State University \\ 401 North 7th Street, Terre Haute, IN 47809, USA \\ Email: Feng-Qi.Lai@indstate.edu \\ Professor Timothy J. Newby \\ Department of Curriculum and Instruction, Purdue University \\ 100 North University Street, West Lafayette, IN 47909, USA \\ Email: newby@purdue.edu
}

Please cite as: Lai, F. Q. \& Newby, T. J. (2012). Impact of static graphics, animated graphics and mental imagery on a complex learning task. Australasian Journal of Educational Technology, 28(1), 91-104. http: / / www.ascilite.org.au/ajet/ajet28/lai.html 